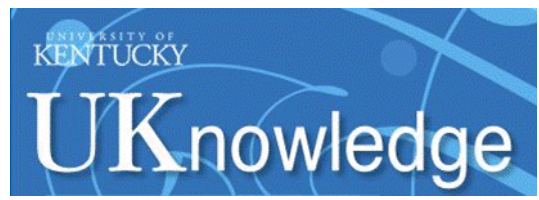

University of Kentucky

UKnowledge

Institute for Sustainable Manufacturing Faculty

Publications

Sustainable Manufacturing

$5-3-2018$

\title{
Analysis of Surface Integrity in Machining of AISI 304 Stainless Steel Under Various Cooling and Cutting Conditions
}

\author{
F. Klocke \\ RWTH Aachen University, Germany \\ B. Döbbeler \\ RWTH Aachen University, Germany \\ S. Lung \\ RWTH Aachen University, Germany \\ S. Seelbach \\ RWTH Aachen University, Germany \\ Ibrahim S. Jawahir \\ University of Kentucky, is.jawahir@uky.edu
}

Follow this and additional works at: https://uknowledge.uky.edu/ism_facpub

Part of the Manufacturing Commons, Metallurgy Commons, and the Sustainability Commons

Right click to open a feedback form in a new tab to let us know how this document benefits you.

\section{Repository Citation}

Klocke, F.; Döbbeler, B.; Lung, S.; Seelbach, S.; and Jawahir, Ibrahim S., "Analysis of Surface Integrity in Machining of AISI 304 Stainless Steel Under Various Cooling and Cutting Conditions" (2018). Institute for Sustainable Manufacturing Faculty Publications. 5.

https://uknowledge.uky.edu/ism_facpub/5

This Conference Proceeding is brought to you for free and open access by the Sustainable Manufacturing at UKnowledge. It has been accepted for inclusion in Institute for Sustainable Manufacturing Faculty Publications by an authorized administrator of UKnowledge. For more information, please contact UKnowledge@lsv.uky.edu. 


\title{
Analysis of Surface Integrity in Machining of AISI 304 Stainless Steel Under Various Cooling and Cutting Conditions
}

\author{
Digital Object Identifier (DOI) \\ https://doi.org/10.1063/1.5034911 \\ Notes/Citation Information \\ Published in AIP Conference Proceedings, v. 1930, issue 1, 070015, p. 1-6.
}

This article may be downloaded for personal use only. Any other use requires prior permission of the author and AIP Publishing.

The following article appeared in AIP Conference Proceedings, v. 1930, issue 1, 070015, p. 1-6 and may be found at https://doi.org/10.1063/1.5034911. 


\section{Analysis of surface integrity in machining of AISI 304 stainless steel under various cooling and cutting conditions}

F. Klocke, B. Döbbeler, S. Lung, T. Seelbach, and I. S. Jawahir

Citation: AIP Conference Proceedings 1960, 070015 (2018); doi: 10.1063/1.5034911

View online: https://doi.org/10.1063/1.5034911

View Table of Contents: http://aip.scitation.org/toc/apc/1960/1

Published by the American Institute of Physics

\section{Articles you may be interested in}

High speed machinability of the aerospace alloy AA7075 T6 under different cooling conditions AIP Conference Proceedings 1960, 070013 (2018); 10.1063/1.5034909

3D FE simulation of semi-finishing machining of Ti6Al4V additively manufactured by direct metal laser sintering AIP Conference Proceedings 1960, 070014 (2018); 10.1063/1.5034910

Mechanics of the Metal Cutting Process. I. Orthogonal Cutting and a Type 2 Chip

Journal of Applied Physics 16, 267 (1945); 10.1063/1.1707586

Process based analysis of manually controlled drilling processes for bone AIP Conference Proceedings 1960, 070025 (2018); 10.1063/1.5034921

Effect of micro-scale texturing on the cutting tool performance

AIP Conference Proceedings 1960, 070027 (2018); 10.1063/1.5034923

A new optimization tool path planning for 3-axis end milling of free-form surfaces based on efficient machining intervals

AIP Conference Proceedings 1960, 070011 (2018); 10.1063/1.5034907 


\title{
Analysis of Surface Integrity in Machining of AISI 304 Stainless Steel under Various Cooling and Cutting Conditions
}

\author{
F. Klocke ${ }^{1)}$, B. Döbbeler ${ }^{1)}$, S. Lung ${ }^{1)}$, T. Seelbach ${ }^{1, \text { a) }}$, I.S. Jawahir ${ }^{2)}$ \\ 1) Laboratory for Machine Tools and Production Engineering (WZL) of RWTH Aachen University, Germany \\ ${ }^{2)}$ Institute for Sustainable Manufacturing (ISM), University of Kentucky, Lexington KY, USA \\ a) Corresponding author: T.Seelbach@wzl.rwth-aachen.de
}

\begin{abstract}
Recent studies have shown that machining under specific cooling and cutting conditions can be used to induce a nanocrystalline surface layer in the workspiece. This layer has beneficial properties, such as improved fatigue strength, wear resistance and tribological behavior. In machining, a promising approach for achieving grain refinement in the surface layer is the application of cryogenic cooling. The aim is to use the last step of the machining operation to induce the desired surface quality to save time-consuming and expensive post machining surface treatments. The material used in this study was AISI 304 stainless steel. This austenitic steel suffers from low yield strength that limits its technological applications. In this paper, liquid nitrogen $\left(\mathrm{LN}_{2}\right)$ as cryogenic coolant, as well as minimum quantity lubrication (MQL), was applied and investigated. As a reference, conventional flood cooling was examined. Besides the cooling conditions, the feed rate was varied in four steps. A large rounded cutting edge radius and finishing cutting parameters were chosen to increase the mechanical load on the machined surface. The surface integrity was evaluated at both, the microstructural and the topographical levels. After turning experiments, a detailed analysis of the microstructure was carried out including the imaging of the surface layer and hardness measurements at varying depths within the machined layer. Along with microstructural investigations, different topological aspects, e.g., the surface roughness, were analyzed. It was shown that the resulting microstructure strongly depends on the cooling condition. This study also shows that it was possible to increase the micro hardness in the top surface layer significantly.
\end{abstract}

\section{INTRODUCTION}

For industrial products, workpiece properties such as fatigue strength, wear resistance and the tribological behavior are of great importance. Recently, it has been shown that a nanocrystalline surface layer can improve these properties. Furthermore, it is well known that a nanocrystalline surface layer can shorten the running-in phase and improve the reliability in a stationary state. [1] Severe plastic deformation (SPD) processes, e.g., surface mechanical attrition treatment (SMAT), are applied to improve the functional performance of products. However, recent studies have shown that the machining process itself can be categorized as a SPD process as well [2]. Under specific conditions machining can be used to induce a nanocrystalline surface layer [3]. Therefore, the cutting process with involved and influencing cutting parameters, tool geometries and cooling conditions has to be adjusted to achieve the most desirable properties.

The demand for austenitic stainless steel has increased enormously during the past years [4]. This material is often chosen because of its high corrosion resistance and its good formability. Nevertheless, most austenitic steels suffer from low yield strength which limits their technological applications. The challenge is to strengthen these materials without compromising their useful properties [5]. The used material for this work was AISI 304 stainless steel. If it is possible to increase the mechanical, topographical and microstructural properties of this material during the machining process, this material can be used in a range of applications. A promising approach for achieving a nanocrystalline surface structure is the application of the cryogenic medium liquid nitrogen. The heat in the cutting zone is removed very quickly, and the dynamic recovery of the microstructure is suppressed [6]. By applying minimum quantity 
lubrication (MQL), the topological aspect, e.g., surface roughness, can be improved by reducing the friction in the cutting zone. In this paper, therefore, liquid nitrogen $\left(\mathrm{LN}_{2}\right), \mathrm{MQL}$ lubrication, as well as a combination of both, were applied and investigated. The results were analyzed for changes in the microstructure, the micro and nano hardness and the surface quality. Thereby, an overall investigation regarding the surface integrity was carried out. The major objective of this study was to use the finish machining process to induce the desired surface integrity. The outcome of this study was expected to pave the way for avoiding expensive and time-consuming post-treatment processes.

\section{EXPERIMENTAL SET-UP}

The test material is austenitic stainless steel AISI 304 (X5CrNi18-10). To ensure comparability, no heat treatment was performed and the material is machined in the delivered state. The main reason was to avoid formation of chromium carbides within the temperature area between 450 and $800{ }^{\circ} \mathrm{C}$. The material contains a single-phase austenitic microstructure with a face-centered cubic (fcc) crystal lattice at room temperature. The annealed state is characterized by very good toughness properties which are retained at extremely low temperature [7]. In the delivered state, the material AISI 304 exhibits a low hardness. The bulk hardness was measured to be $\mathrm{H}=187 \mathrm{HV} 0.1$. The initial grain size was $d_{g}=20-30 \mu \mathrm{m}$.

The face turning experiments were conducted on a CNC lathe. The tool cutting edge angle was $\kappa_{\mathrm{r}}=45^{\circ}$. It was reported that using large rounded cutting edge radii, in a combination with cryogenic cooling, is leading to enhanced surface properties in terms of improved surface finish and significant grain refinement with increased hardness [8]. Therefore, indexable inserts with a large rounded cutting edge radius, $\mathrm{r}_{\beta}=81 \mu \mathrm{m}$, were chosen. All experiments were carried out with coated cemented carbide inserts provided by Sandvik. The main cutting edge had a clearance angle of $\alpha=0^{\circ}$ and a rake angle of $\gamma=9^{\circ}$. The tool cutting edge inclination was $\lambda_{s}=-7^{\circ}$. The cutting speed was set at $\mathrm{v}_{\mathrm{c}}=200 \mathrm{~m} / \mathrm{min}$, the depth of cut to $a_{p}=0.2 \mathrm{~mm}$, and the feed rate was varied in four steps from $f=0.075 \mathrm{~mm}$ to $0.15 \mathrm{~mm}$. Figure 1(a) shows the experimental set-up. Cryogenic flank cooling was applied as cooling strategy. The pressure of the $\mathrm{LN}_{2}$ tank was set at $p=10.34$ bar (^ 150 psi). Liquid nitrogen $\left(\mathrm{LN}_{2}\right)$ was applied via a sealed pipe and a copper pipe to the cutting zone. At the exit of the cooling channel, at atmospheric pressure, liquid nitrogen reaches a temperature of $\mathrm{T}=-196^{\circ} \mathrm{C}$ [4]. Besides, a combination of cryogenic flank cooling and MQL from the rake face was investigated (hereafter referred to as CryoMQL). For comparison, MQL lubrication, as well as conventional flood cooling, tests were included in the test series. Currently, flood cooling is state-of-the-art for machining stainless steel in the industry. The four different cooling strategies are shown in Fig. 1(b).

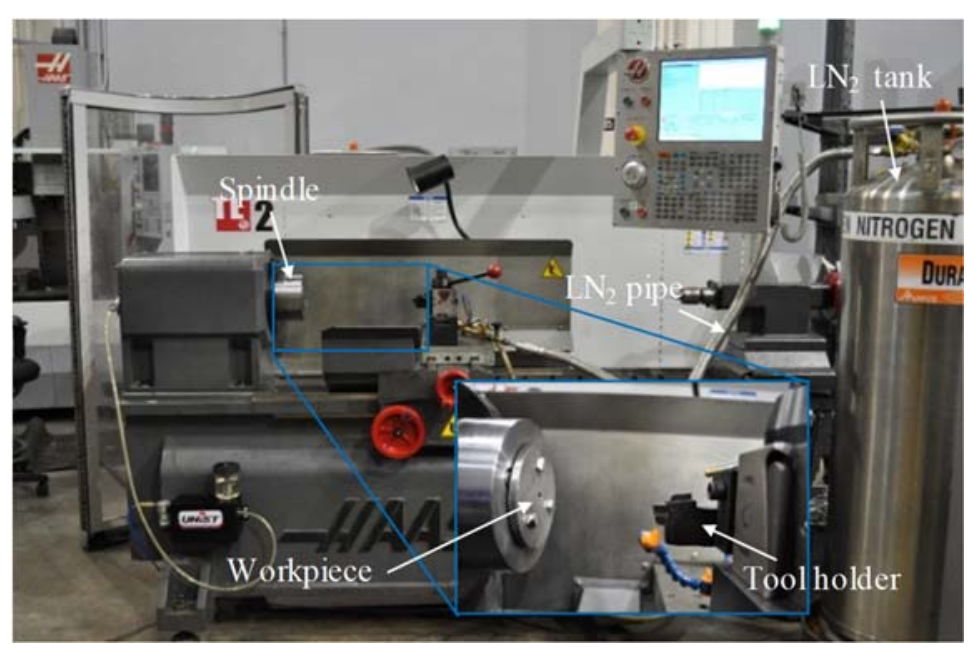

(a)
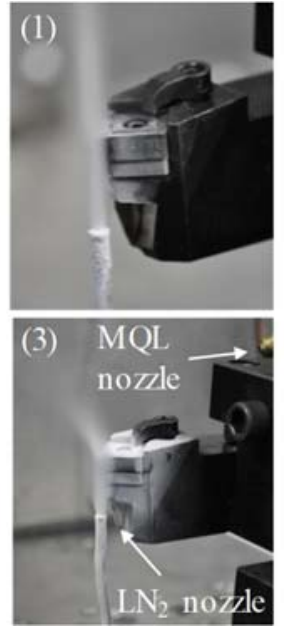

(b)
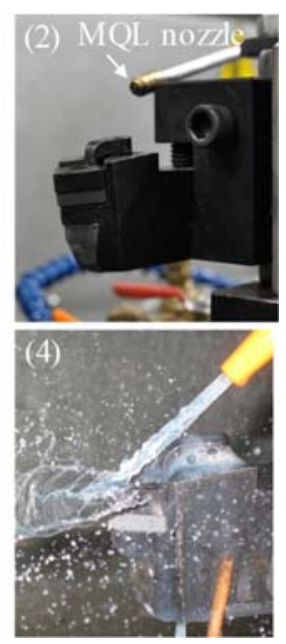

FIGURE 1. (a) Experimental set-up and (b) the investigated cooling lubrication strategies (1) Cryo flank, (2) MQL, (3) CryoMQL, and (4) conventional flood cooling.

In a first step, machined samples of the material were metallurgically prepared by hot melting, grinding, polishing and etching. The microstructure was examined using a Nikon EPHIPHOT 300 optical microscope. For more detailed 
analysis, scanning electron microscopy (SEM) and focused ion beam (FIB) analyses were included into the experiments. The micro-hardness measurements were conducted on SUN-TECH Model FM1 hardness tester. The applied load was $F=0.1 \mathrm{kp}(\hat{=} 0.98 \mathrm{~N})$ and the dwell time was $t=15 \mathrm{~s}$. Also, a nano indentation test was conducted using a NanoTest Vantage from Micro Materials.

\section{RESULTS AND DISCUSSION}

Several evaluation criteria were investigated. The first evaluation criterion is the effect of the machining process on the resulting microstructure. Figure 2 shows the surface rim zone and the affected layer after machining with CryoMQL (a), and in comparison with machining with MQL lubrication (b). The microstructure images reveal a significant difference in the layer thickness when MQL machining is compared with CryoMQL. Same cutting parameters were applied for both cooling strategies. Consequently, the mechanical loads are the same. The application of cryogenic cooling removes the heat from the cutting zone very quickly. The dynamic recovery of the microstructure is suppressed, and a larger affected surface layer is produced.

Also, Fig. 2a shows a white layer on the surface with a thickness of approx. $19 \mu \mathrm{m}$. These white layers, also called severe plastic deformation (SPD)-layers, occur after high plastic deformation and high cooling rates [9]. The high cooling rates are achieved by the application of cryogenic cooling. The high plastic deformation is a result of different process parameters such as a small depth of cut and an adjusted tool geometry with a large rounded cutting edge radius $r_{\beta}$ and a small effective rake angle $\gamma$. The ploughing effect becomes more important resulting in squeezing of the material and deeper plastic deformation. Another important parameter is the feed rate $f$. At higher feed rates the passive force is increased due to an increase in material removal. With higher passive forces the maximum stresses and penetration depth are enlarged [10,11]. Usually, white layers are not desired. A higher hardness together with lower ductility lead to an increase in the formation and propagation of cracks, which decrease the fatigue resistance of dynamically loaded components. Due to safety concerns, it is usually important to prevent its occurrence [12]. Thus, it is generally accepted that white layers consists of nanocrystalline structures, which develop through dynamic recrystallization and grain subdivision through severe plastic deformation [13]. Depending on the application, white layers may become beneficial because of their positive influence on tribological properties [14].

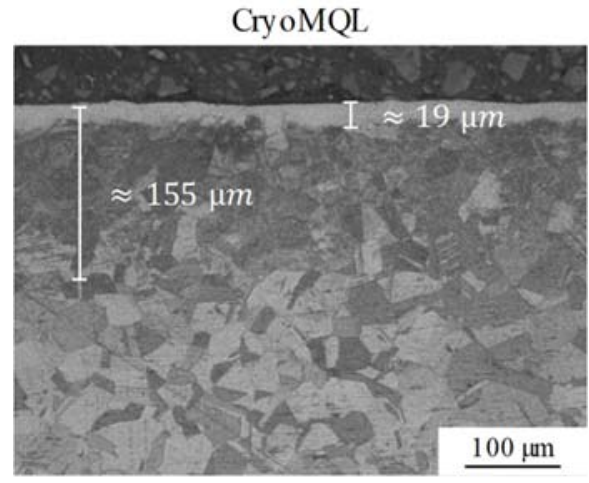

(a)

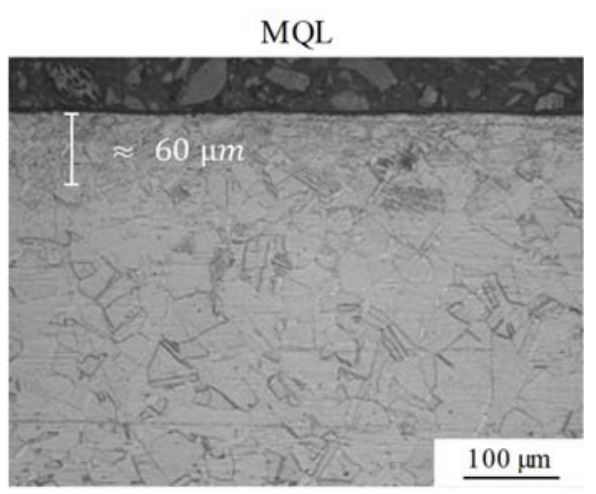

(b)

FIGURE 2. Microstructure resulting from different cooling strategies when machining with $f=0.15 \mathrm{~mm}$

The grain size within the white layer was analyzed with FIB and SEM. Three different areas were determined (see Fig. 3(a). At the top surface, a layer with an average grain size below $100 \mathrm{~nm}$ was found. By definition, grains that are smaller than $100 \mathrm{~nm}$ are considered as nano-sized grains [15]. This 'Nano-Layer' had a thickness of about $2.15 \mu \mathrm{m}$. Below that first layer, a secondary layer was found with an average grain size up to $500 \mathrm{~nm}$. This refined layer had a thickness of approximately $18 \mu \mathrm{m}$. Below these two layers, a transition layer can be defined merging into the bulk material, obtaining almost the same grain size, but showing a significantly higher density of dislocations. Comparable results were found in a previous work [16]. The underlying effect for grain refinement is dynamic recrystallization (DRX). During plastic deformation at elevated temperatures, dislocations serve as nuclei, and new grains are formed. The necessary thermal activation energy is coming from the thermal energy produced in the cutting process. The plastic deformation and the temperature were high enough to start the process of grain refinement. 


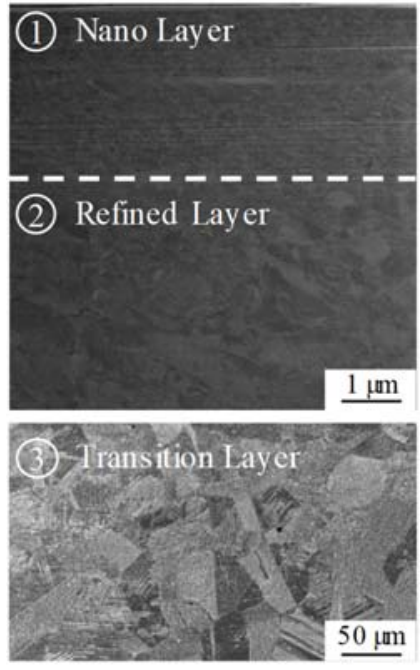

(a)

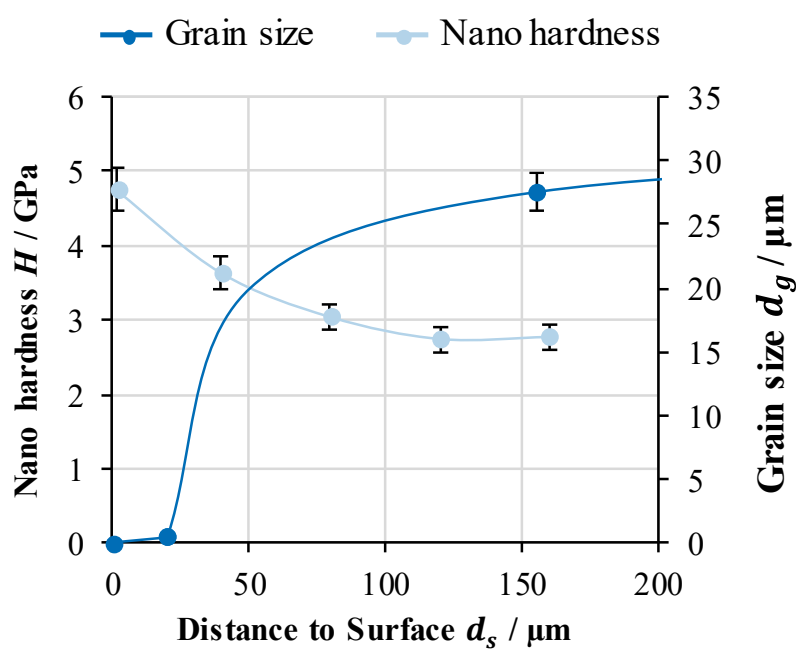

(b)

FIGURE 3. (a) SEM images of the refined layer, and (b) grain size and nano hardness developed at varying depths in the machined layer at $f=0.15 \mathrm{~mm}$ with CyroMQL

According to [4], the hardness in the surface layer can be increased due to work-hardening as well as grain refinement. Figure 4 shows the resulting surface hardness at varying depths in the machined layer for each cooling strategy and for a feed rate of $f=0.15 \mathrm{~mm}$. Before the machining trials, the bulk hardness was measured to be 186 HV0.1. For each sample, the hardness was measured in $25 \mu \mathrm{m}$ steps because significant changes were expected close to the machined surface. The results show a large impact of the cooling and/or lubrication strategy. The maximum hardness was measured on the surface for all samples, followed by decreasing values towards the bulk material. Depending on the cooling strategy, the decrease took place very rapidly at varying depths below the machined surface. Conventional flood cooling showed the fastest decrease of the hardness. The surface layer exhibit a harder layer, which is followed by a softer one. The hardness increase is due to work-hardening and grain refinement. As shown in Fig. 4, the hardness development after machining with flood cooling crosses the bulk material's hardness. This decrease in hardness, compared to the initial one, can be related to thermal softening. The same development is shown after cryogenic flank cooling, as well as after machining with MQL lubrication. For CryoMQL machining, after which the highest hardness values were found, the profile reaches the baseline close to a depth of $500 \mu \mathrm{m}$ at the end of the measuring scale.

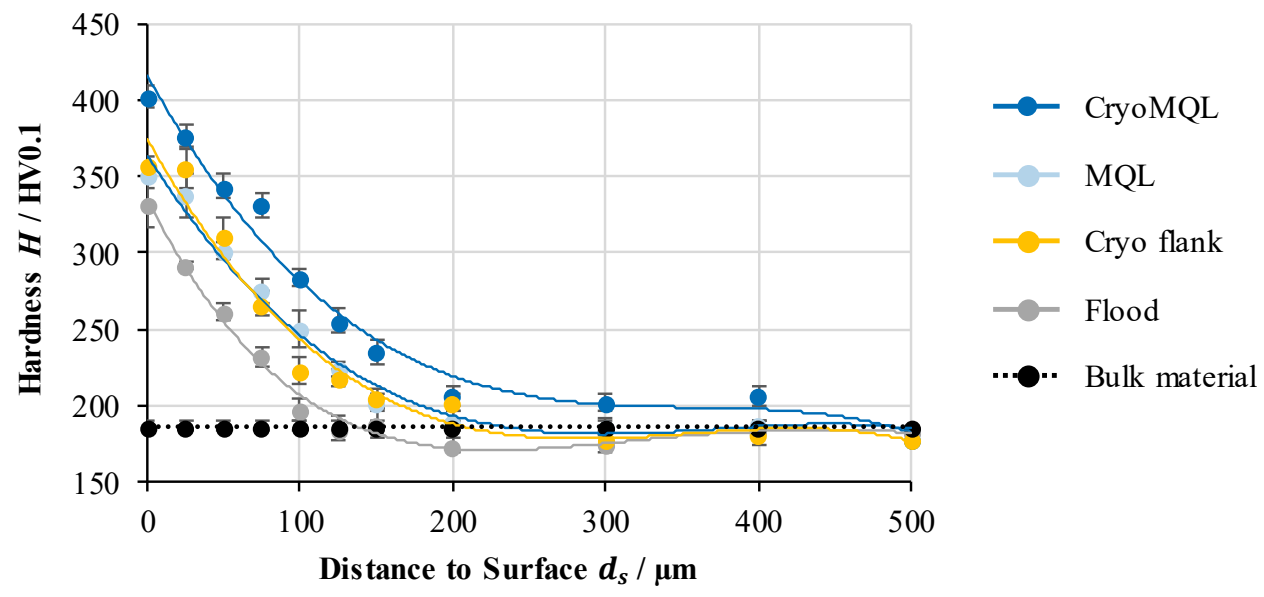

FIGURE 4. Hardness variation at varying depths below the machined surface for each cooling method 
The sample exhibiting the SPD-layer after CryoMQL machining with an averaged grain size of $40-100 \mathrm{~nm}$ was analyzed with nano indentation tests to investigate the increase in hardness due to grain refinement. The measurement on nano-scale enables the possibility to place the indentation within the nanocrystalline surface layer. Figure $3(\mathrm{~b})$ shows both the results of the nano hardness measurements and the development of the grain size as a function of the distance from the machined surface. It can be seen that there is a correlation of grain size with hardness. With increasing grain size, the hardness decreases. The 'Nano Layer' with a grain size between $40-100 \mathrm{~nm}$ exhibits a hardness of $499.6 \mathrm{HV}$. The hardness development is similar to the well-known Hall-Petch relation. As soon as a critical grain size is reached, the strengthening effect of the Hall-Petch relation shifts into a softening effect. It can be concluded that this critical grain size was not reached during the experiments presented. It can be concluded, that the increase in hardness can be attributed to both work-hardening and grain refinement.

To evaluate the surface quality, microscopic and SEM images of the machined surfaces were taken. Depending on the cooling strategy and the feed rate, the surface shows more or less defects. The best results were achieved when conventional flood cooling or MQL lubrication were applied. Applying cryogenic coolant from the flank face to the cutting zone resulted in a large number of defects which occur periodically. For further analysis, SEM images were taken (see Fig. 5(a)). Additionally, an EDX analysis was conducted to determine the structure and the type of material of causing these defects. Figure 5(a) shows the results after machining with CryoMQL at a feed rate of $f=0.15 \mathrm{~mm}$. The EDX analysis, see Fig. 5(b), indicates that the material on the surface is AISI 304. This leads to the conclusion that the defects resulted of the formation of built-up edges. Particles of the built-up edges slipped over to the flank face of the machined surface, and remained as surface damage. The basic mechanism for the appearance of built-up edges is adhesion. Highly reinforced layers of the machined material bonds to the tool and take over the function of the tool cutting edge [7]. Austenitic stainless steels have a high tendency to adhesion with the cutting tool material. The formation of built-up edges during machining of this material is a common problem. This is mainly due to the high plastic deformability, which result of the face-centered cubic lattice structure. This occurrence depends on the cutting temperature with a maximum at a certain cutting temperature. To avoid the formation of built-up edges, usually, the cutting speed is increased to raise the cutting temperature. Reducing the cutting temperature by applying cryogenic cooling shifts the extremes of built-up edges formation to higher cutting speeds [7].

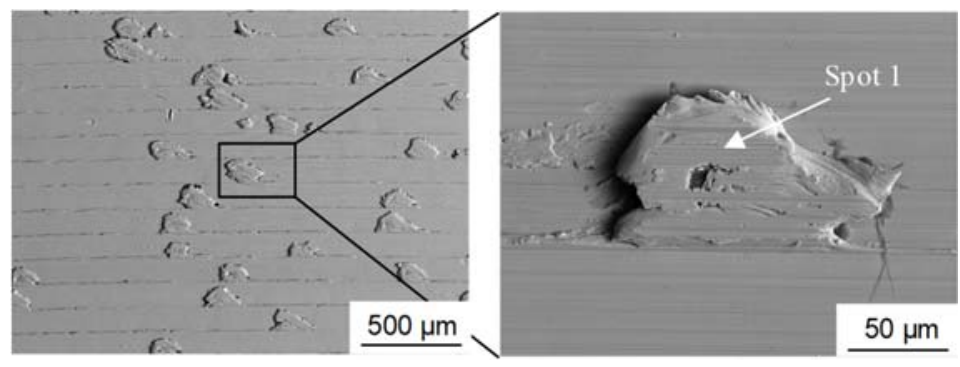

(a)

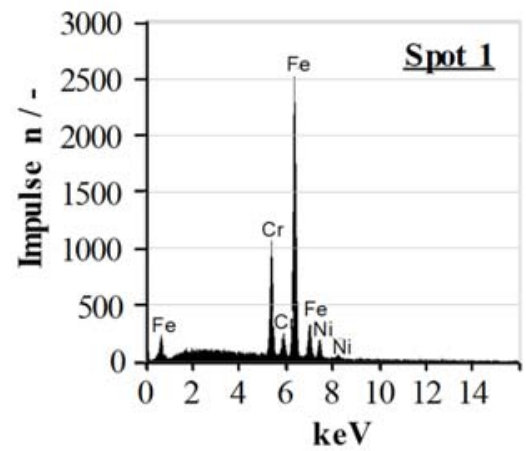

(b)

FIGURE 5. (a) Topography after machining with CryoMQL, and (b) EDX analysis of the built-up edges on the machined surface

\section{CONCLUSIONS}

The overall objective of this research was to use the finishing step of the machining process to obtain desired surface properties. Therefore, specific cutting conditions were investigated within this paper. It can be concluded, that it is possible to achieve a nanocrystalline surface layer in turning when using a cutting tool with a large cutting edge radius under finish cutting conditions and the use of cryogenic coolant. Also, it was shown that the refined surface layer can enhance properties in terms of the surface hardness only to an extent, but has its downside on the surface quality, where numerous built-up edges were found. 


\section{ACKNOWLEDGMENTS}

The authors gratefully thank the Institute for Sustainable Manufacturing (ISM) at the University of Kentucky for their support for this research work, especially for the experimental work conducted with technical support in the facilities of ISM. The authors also would like to acknowledge Marvin Hardt and Dipl.-Ing. Sven Lung for their help with experimental work and analysis of results.

\section{REFERENCES}

1. Ambrosy, F.; Zanger, F.; Schulze, V.; Jawahir, I. S.: An experimental study of cryogenic machining on nanocrystalline surface layer generation. Procedia CIRP (2014) pp. 169-174.

2. Guo, Yang; Saldana, Christopher; Dale Compton, W.; Chandrasekar, Srinivasan: Controlling deformation and microstructure on machined surfaces. Acta Materialia (2011) pp. 4538-4547.

3. Buchkremer, S.; Klocke, F.: Modeling nanostructural surface modifications in metal cutting by an approach of thermodynamic irreversibility. Continuum Mechanics and Thermodynamics (2017) pp. 271-289.

4. Jawahir, I. S.; Attia, H.; Biermann, D.; Duflou, J.; Klocke, F.; Meyer, D.; Newman, S. T.; Pusavec, F.; Putz, M.; Rech, J.; Schulze, V.; Umbrello, D.: Cryogenic manufacturing processes. CIRP Annals - Manufacturing Technology (2016) pp. 713-736.

5. Lu, K.; Yan, F. K.; Wang, H. T.; Tao, N. R.: Strengthening austenitic steels by using nanotwinned austenitic grains. Scripta Materialia (2012) pp. 878-883.

6. Jawahir, I. S.; Brinksmeier, E.; M'Saoubi, R.; Aspinwall, D. K.; Outeiro, J. C.; Meyer, D.; Umbrello, D.; Jayal, A. D.: Surface integrity in material removal processes. CIRP Annals - Manufacturing Technology (2011) pp. 603-626.

7. Klocke, F.: Manufacturing Processes 1 (Berlin, Heidelberg, New York,2011) 517.

8. $\quad \mathrm{Pu}, \mathrm{Z}$;; Outeiro, J. C.; Batista, A. C.; Dillon, O. W.; Puleo, D. A.; Jawahir, I. S.: Enhanced surface integrity of AZ31B Mg alloy by cryogenic machining towards improved functional performance of machined components. International Journal of Machine Tools and Manufacture (2012) pp. 17-27.

9. Fredj, N. B.; Sidhom, H.: Effects of the cryogenic cooling on the fatigue strength of the AISI 304 stainless steel ground components. Cryogenics (2006) pp. 439-448.

10. Mayer, P.; Skorupski, R.; Smaga, M.; Eifler, D.; Aurich, J. C.: Deformation induced surface hardening when turning metastable austenitic ateel AISI 347 with different cryogenic cooling strategies. Procedia CIRP (2014) pp. 101-106.

11. Mayer, P.; Kirsch, B.; Müller, R.; Becker, S.; Harbou, E. v.; Aurich, J. C.: Influence of cutting edge geometry on deformation induced hardening when cryogenic turning of metastable austenitic stainless steel AISI 347. Procedia CIRP (2016) pp. 59-62.

12. Ulutan, D.; Ozel, T.: Machining induced surface integrity in titanium and nickel alloys. International Journal of Machine Tools and Manufacture (2011) pp. 250-280.

13. Bushlya, V.; Zhou, J. M.; Lenrick, F.; Avdovic, P.; Stahl, J-E.: Characterization of white layer generated when turning aged Inconel 718. Procedia Engineering (2011) pp. 60-66.

14. Ambrosy, F.; Zanger, F.; Schulze, V.: FEM-simulation of machining induced nanocrystalline surface layers in steel surfaces prepared for tribological applications. CIRP Annals - Manufacturing Technology (2015) pp. 6972 .

15. Padmanabhan, K. A.: Mechanical properties of nanostructured materials. Materials Science and Engineering: $A$ (2001) pp. 200-205.

16. Nikitin, I.; Altenberger, I.; Maier, H. J.; Scholtes, B.: Mechanical and thermal stability of mechanically induced near-surface nanostructures. Materials Science and Engineering: A (2005) pp. 318-327. 